\title{
ENSAIO DE DIGESTIBILIDADE COM BOVINOS EM GAIOLAS, DE UM FENO DE CAPIM-ELEFANTE NAPIER (Pennisetum purpureum, Schum).
}

\author{
lício VELLOSO * \\ Washington Coelho NOVAES ** \\ Ronaldo Lima VILLELA ** \\ Lineu Pereira de OLIVEIRA **
}

RFMV-A/13

\begin{abstract}
VELLOSO, L.; NOVAES, W.C.; VILLELA, R.L.; OLIVEIRA, L.P. Ensaio de digestibilidade com bovinos em gaiolas, de um feno de capim-elefante Napier (Pennisetum purpureum, Schum). Rev. Fac. Med. vet. Zootec. Univ. S.Paulo, 14(1): 101-111, 1977.
\end{abstract}

RESUMO: Utilizando três bovinos mestiços holundês castrados, foi realizado no C.I.Z.I.P. "Fernando Costa" em Pirassununga (S.P.), ensaio de digestibilidade (aparente), em gaiolas, de um feno de capim-elefante Napier (Pennisetum purpureum Schum), confeccionado 63 dias após controle de altura, efetuado com animais em pastejo. As observaçôes tivera ın duração de 15 dias, sendo os 5 primeiros para adaptaçäo dos animais ao alimento, em estábulo, e 10 dius subseqüentes nas gaiolas. Apenas os últimos 7 dias foram aproveitados para efeito de controle e amostragem do alimento, das fezes e da urina. Os resultados médios encontrados nas análises bromatológicas foram: Matéria seca (M.S.) 87,75\%; Protetna bruta (P.B.) 10,94\%; Extrato etéreo (E.E.) 2,57\%; Fibra bruta (F.B.) 30,81\% e Extrativos náo nitrogenados (E.N.N.) 36,29\% Após o levantamento dos dados da digestibilidade, foram obtidos os seguintes coeficientes de digestibilidade: M.S. 58,76\%; P.B. 59,14\%; E.E. 61,72\%; F.B. 73,81\% e E.N.N. 59,95\%, sendo que os Nutrientes digest iveis tota is (N.D.T.) alcangaram 54,54\%

UNITERMOS: Alimentos, digestibilidade *; Feno *; Forragens *.

\section{INTRODUÇÃO E LITERATURA}

No Brasil Central há estacionsdidade de clima bem definida; com verão (outubrobril) de temperaturas altas e chuvas abundantes, e inverno de temperaturas mais baixas e precipitações reduzidas. Essa estacionalida. de, condiciona o crescimento das forrageiras.

PEDREIRA $^{12}$ (1973) medindo o efeito dessa estacionalidade, revelou, que a produção de forrageiras nessa região é de 80 a $90 \%$ no verão e 10 a $20 \%$ no inverno.

Com o intuito de diminuir as condi- ções adversas que se apresentam na época da seca, os pecuaristas dessa região, inicialmente, procuraram o uso de capineiras.

MUNIZ et alii ${ }^{9}$ (1972) trabalhando com capim-elefante variedade "Mineiro", analisaram o método tradicional de oferecimento das sobras maduras, obtendo como resultado, perdas diárias médias de 153g/animal, em novilhos Nelore. Nesse trabalho foi também avaliada a silagem desse mesmo capim, a qual enhbora proporcionando um ganho diário médio de $158 \mathrm{~g} /$ animal, revelou-se economicamente insatisfatória.

\footnotetext{
* Professor Livre-Docente Departamento de Produção Animal da Faculdade de Medieina Veterinárla e Zootecnia da USP.

* * Aluno do 9\% semestre da Faculdade de Medicina Veterinária e Zootecnia da USP.
} 
Uma outra opçăo que hoje se apresenta, aos pecuaristas, é a prática da fenação das forrageiras. Essa atividade, até há pouco tempo, apresentava sérios incovenientes, já que era uma operação demorada, oferecendo demasiados riscos de perdas, por excesso de chuvas, manuseio impróprio ou secagem excessiva. Atualmente, entretanto, observa-se movimentação de pecuaristas e empresários no sentido de se aplicar tecnologia moderna, visando minimizar esses problemas. Além disso, a prática da fenação, oferece algumas vantagens, quanto ao transporte e ao armazenamento, pois trabalha-se com maior proporção de matéria seca em relação à silagem.

Baseandorse nos fatos acima expostos, torna-se evidente a importância de trabalhos acerca da digestibilidade de fenos produzidos com forrageiras dessa região.

Diversas variedades de capirn-elefante são cultivadas atualmente no Brasil, tendo sido já bastante estudadas.

PEDREIRA $^{13}$ (1975) comparando cinco variedades de capim elefante (Pennisetum purpureum, Schum), que foram Napier, Mineiro, Taiwan A-143, Taiwan A-144 e Taiwan A-148, encontrou diferenças significativas na produção de matéria seca somente para a variedade Taiwan A-148, sendo essa inferior às demais. Quanto aos teores de proteina bruta e fibra bruta não houve diferenças estatisticamente válidas.

PACOLA $^{10}$ (1974) estudando oito variedades de capim elefante, classificou-as em ordem decrescente pela produção de massa verde por hectare, num periodo de 171 dias de crescimento a partir de fevereiro. Os resultados foram: Taiwan A.143 - 71.802 kg; Taiwan A-146 - 69.791 kg; Mineiro $53.343 \mathrm{~kg}$; Porto Rico - $53.866 \mathrm{~kg}$; Merker - 46.854 kg; Merkeron Comum - 44.968 kg; Taiwan A-25 - 42.687 kg; e Merkeron México $-27.270 \mathrm{~kg}$.

PACOLA ${ }^{11}$ (1972) analisou a apetibilidade do capim-elefante em diferentes variedades e obteve os melhores índices, em ordem decrescente, para as variedades Merkeron México, Merkeron Comum, Taiwan A-146, Porto Rico, Mineiro, Taiwan A-25, Taiwan A-1 43 e Merker.

O capim-elefante, nas suas diversas variedades, constitui hoje uma das plantas for- rageiras, mais utilizadas no inverno, devido ao seu alto rendimento por unidade de área. Entretanto, numerosos experimentos realizados nos últimos anos, visando obter informa. ções acerca da sua produtividade e dos seus constituintes químicos-bromatológicos, mostram existir uma correlação negativa, entre altos rendimentos em massa e a adequada composição química da forrageira.

SILVEIRA et aliii ${ }^{16}(1974)$ obtiveram dados, que permitem concluir que à medida que o capim-elefante avança no seu ciclo vegetativo, ocorre uma redução em seu valor nutritivo, uma vez que as frações solúveis são inversamente proporcionais às fraçốes fibrosas e à maturidade das forragens.

ANDRADE \& GOMIDE ${ }^{1}$ (1972) trabalhando com a variedade Taiwan A-146, obtiveram valores que comprovam, que o valor nutritivo do capim-elefante é inversamente proporcional à sua idade de corte. Todavia, esse valor nutritivo cai de forma mais brusca, entre as idades de 28 a 56 dias, suavizando-se essa queda a partir dessa idade.

BRITTO et alii ${ }^{3}(1965)$ citam, que os cortes menos freqüentes, apresentam maior produção de forragem, porém, com menor teor de proteína e maior conteúdo de fibra, A produção de proteína por hectare foi maior, quando as plantas foram cortadas a cada quatro semanas.

FONSECA ${ }^{4}$ (1965) estudando a digestibilidade (aparente) dos capins Guatemala e elefante variedade Napier, utilizando carneiros e procedendo a coleta total de fezes, com separação de urina, concluiu que os coeficientes de digestibilidade foram menores nos capins de idade mais avançada. Constatou ainda que os teores de fibra aumentavam com a idade do corte, enquanto que os teores de proteína bruta e extrato etéreo diminuiam com a mesma. A relação nutritiva foi consideravelmente mais larga, nos capins de corte mais elevado, principalmente no elefante Napier.

SILVA ${ }^{14}$ (1965) trabalhando com oito forrageiras, dentre as quais o capim-elefante Napier, utilizando o método "in vitro" com líquido de rúmen, constatou um aumento significante na porcentagem de celulose e um decréscimo da digestibilidade, com o avançar da idade das forrageiras. $\mathrm{O}$ elefante 
Nápièr aumentou de 32,8 para $39,3 \%$ sua porcentagem de celulose e decresceu na digestibilidade da matéria seca de 88,0 para $72,0 \%$.

VIEIRA \& GOMIDE $^{17}$ (1968) pesquisando três variedades de capim-elefante, acerca de seus teores de proteína bruta e celulose, quando cortados aos 28,54 e 86 dias de idade, obtiveram respectivanente, as seguintes médias: $20,4 \%$ e $28,0 \%$; $14,2 \%$ e $31,8 \%$; $9,3 \%$ e $37,1 \%$.

KOK et alii ${ }^{5}$ (1946) trabalhando com feno de capim-elefante, obtiveram coeficientes de digestibilidade que foram os seguintes: M.S. 70,5\%; P.B. 63,0\%; E.E. 58,0\%; F.B. 66,0\%; E.N.N. 69,5\%. Quanto à análise bromatológica do feno da variedade Napier, cortado a $1,80 \mathrm{~m}$ de altura, os autores obtiveram: M.S. 90,00\%; P.B. 6,07\%; E.E. 0,88\%; F.B. $27,63 \%$; E.N.N. 48,26\% e Matéria Mineral (M.M.) 7,16\%

MELOTTI \& $\mathrm{LUCCI}^{7}$ (1969) comparando o capim-elefante Napier com o capim fino (Brachiaria mutica), através da digestibilidade (aparente), em ovinos, obtiveram os seguintes resultados bromatológicos para o capim-elefante: M.S. $24,46 \%$; P.B. $13,46 \%$; F.B. $31,73 \%$; E.N.N. $42,36 \%$; E.E. $3,35 \%$ e Energia Bruta (E.B.) $4,561 \mathrm{cal} / \mathrm{g}$.

MELOTTI \& PEDREIRA ${ }^{8}(1970 / 71)$ em experimento análogo ao anterior, obtiveram com o capim-elefante Napier, cortado aos 58 dias cie idade os seguintes indices: M.S. $19,54 \%$; P.B. $7,01 \%$; F.B. $33,77 \%$; E.N.N. $43,08 \%$; E.E. $3,56 \%$; M.M. $12,58 \%$ e E.B. $4,270 \mathrm{cal} / \mathrm{g}$. Já o mesmo capim cortado aos 66 dias de idade apresentou: M.S. $15,26 \%$; P.B. $7,73 \%$; F.B. $36,38 \%$; E.N.N. $38,59 \%$; E.E. $3,12 \%$; M.M. $14,18 \%$ e E.B. $4,4,94 \mathrm{cal} / \mathrm{g}$.

SILVA \& GOMIDE $^{15}$ (1967) estudando a digestibilidade (aparente), de gramíneas do Brasil Central - gordura (Melinis minutiflora, Beauv) - pangola (Digitaria pentzii, Stent) - sempre verde (Panicum maximum, Jacq), com idades de 2,4,6 e 8 meses, obtiveram importantes conclusões. $O$ experimento foi conduzido com ovinos e os autores puderam concluir o seguinte:
1 - Não houve diferança no teor de matéria seca entre os capins estudados, mas verificou-se diferença, altamente significativa, no teor de matéria seca entre os estádios de maturação considerados. A medida que avançava o estádio de maturação, havia um aumento no teor de matéria seca dos capins.

2 - Não houve diferença significativa entre as espécies de gramíneas estudadas, com relação ao consumo de matéria seca, mas a diferença entre as idades de corte foi altamente significativa.

3 - Houve um decréscimo linear no consumo de matéria seca, à medida que aumenta o estádio de maturação dos capins.

4 - Houve diferença altamente significativa no coeficiente de digestibilidade (aparente), da matéria seca, tanto entre as espécies de gramíneas como entre as idades estudadas.

5 - Observou-se um decréscimo no coeficiente de digestibilidade à medida que aumentou o estádio de maturaçăo.

6 - Em termos de consumo de matéria seca digestível, verificou-se, diferença altamente significativa, entre as espécies de gramineas e entre as idades estudadas.

7 - Com relação ao teor de matéria seca digestível das três gramíneas estudadas, năo foi verificada diferença entre as idades de corte.

\section{MATERIAL E MÉTODOS}

A forrageira utilizada no presente trabalho foi o capim-elefante Napier (Pennisetum purpureum, Schum), obtido de uma ârea com 19,8 hectares formada em dezembro de 1972, tendo recebido na ocasião a seguinte adubação:

- $2.500 \mathrm{~kg} / \mathrm{ha}$ de calcáreo.

- $625 \mathrm{~kg} / \mathrm{ha}$ de uma fórmula 14-18-8*, com $6 \%$ de Aldrin.

Posteriormente foram ainda efetuadas mais duas adubações, sendo uma no dia 08/03/75, com $208 \mathrm{~kg} / \mathrm{ha}$ de Nitrocálcio e outra no dia 23/10/75, com uma fórmula 6-10-8*

\footnotetext{
* Nas fórmulas citadas, os adubos continham Amônea, Superfosfato simples e Cloreto de Potássio
} 
A área referida foi pastejada até $22 / 12 / 75$, e o corte, para fenaçăo, feito com o auxilio de máquina colhedeira-trituradoura modelo 34, marca John Deere, efetuado dia $23 / 02 / 76$, quando o "stand" apresentava-se com altura aproximada de um metro. Após a colheita, o material picado foi esparramado em terreiro, para secagem, tendo sofrido incidência de chuva naquela ocasião.

0 feno assim obtido, foi considerado suficientemente seco para estocagem, após trểs dias de exposição ao sol.

No ensaio de digestibilidade, foram utilizados três bovinos mestiços holandês (castrados), número julgado suficiente por McDONALD et alii ${ }^{6}$ (1973), para trabalhos dessa natureza. Os referidos animais foram previamente submetidos ao consumo do feno, por cinco dias, sendo então, levados às gaiolas de metabolismo, onde permaneceram durante dez dias; sendo os três primeiros, como adaptação às gaiolas e os sete subseqüentes para efeito de controle e coleta de amostras.

As gaiolas construídas de madeira, eram providas de comedouro, bandeja coletora de fezes e funil para coleta de urina.

0 formecimento de água foi efetuado três vezes ao dia, registrando-se os consumos verificados. Ao feno oferecido diariamente, foram acrescentados trinta gramas de suplemento mineral completo.

Tomou-se o cuidado para que a quantidade de feno colocada à disposição de cada animal, diariamente, fosse superior à sua capacidade de ingestão. Para tanto, adotou-se como referência, os consumos dos dias anteriores.

As amostras das fezes e da urina de cada animal, foram colhidas diariamente durante sete dias, sempre pela manhã, precedidas de homogeneização do material. As amostras, uma vez identificadas, foram conservadas em congelador, até o término do período de coleta, quando então aquelas pertencentes ao mesmo animal, foram agrupadas, novamente misturadas e finalmente retiradas as alíquotas que serviram às análises químicas.

Os métodos analíticos seguidos foram aqueles recomendados pelo A.O.A.C. ${ }^{2}$ (1955).

\section{RESULTADOS}

Na tabela ne 1, encontra-se o controle do consumo do feno.

Na tabela nQ 2, é apresentado o Balanço da Matéria Seca para cada animal, a média dos três animais e respectivos desvios.

Nas tabelas nos $3,4,5,6,7,8,9,10,11$ e 12 encontram-se as análises bromatológicas $e$ os balanços, respectivamente de, Nitrogênio, Proteína Bruta, Extrato Etéreo, Fibra Bruta e Extrativos Não Nitrogenados, com suas médias e desvios.

Na tabela n९ 13, são apresentados os valores de energia do feno utilizado, em N.D.T. e em Kcal/kg, utilizando a constante de conversão preconizada por McDONALD et alii $^{6}$ (1973).

\section{DISCUSSĀO}

No presente experimento, utilizando-se de feno de capim-elefante, cortado na idade de 63 dias, constatou-se um teor de proteína bruta de 10,94\%; enquanto que VIEIRA \& GOMIDE $^{17}$ (1968) trabalhando, também, com capim-elefante cortado nas idades de 54 e 86 dias, observaram os respectivos teores de proteína bruta, 14,2\% e 9,3\%. Verifica-se, portanto, que a idade de corte, do capim-elefante utilizado, situa-se entre as idades de corte com as quais trabalharam aqueles autores, e que o teor de proteína bruta assume a mesma posição intermediária aos observados por eles.

Os teores dos diferentes nutrientes encontrados neste ensaio, foram inferiores aos constatados por KOK et alii (1946), no tocante à M.S. $87,75 \%(90,00 \%)$ e E.N.N. $36,29 \%(48,26 \%)$, e superiores para P.B. $10,94 \%(6,07 \%)$; E.E. $2,57 \%(0,88 \%)$ e F.B. $30,81 \%(27,63 \%)$. Quanto aos Coeficientes de Digestibilidade, observaram-se indices inferiores para M.S. 58,76\% (70,50\%); P.B. $59,14 \%(63,00 \%)$ e E.N.N. 59,95\% (69,50\%) e superiores para E.E. $61,72 \%(58,00 \%)$ e F.B. $73,81 \%(66,00 \%)$.

MELOTTI \& LUCCI' (1969) efetuando análise bromatológica do capim-elefante 


\begin{tabular}{|c|c|c|c|c|c|}
\hline & $\begin{array}{l}\bar{a} \\
\vdots \\
\hat{j}\end{array}$ & $\frac{\text { ฟ }}{\frac{\text { จิ }}{0}}$ & 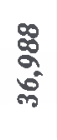 & $\begin{array}{l}\hat{s} \\
\bar{n} \\
\bar{n}\end{array}$ & 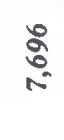 \\
\hline 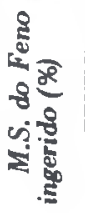 & 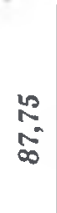 & $\frac{1}{\infty}$ & $\begin{array}{l}\stackrel{2}{\infty} \\
\stackrel{\infty}{\infty}\end{array}$ & $\begin{array}{l}2 \\
\stackrel{\infty}{\infty} \\
\infty\end{array}$ & $\begin{array}{l}1 \\
1\end{array}$ \\
\hline 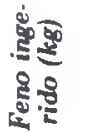 & $\begin{array}{l}\bar{\vdots} \\
\stackrel{5}{+}\end{array}$ & $\begin{array}{l}\text { ฟे } \\
\text { ฟิ }\end{array}$ & $\frac{\text { ฟี }}{\text { สิ }}$ & 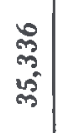 & $\underset{\infty}{\stackrel{\circ}{*}}$ \\
\hline 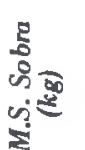 & $\frac{n}{n}$ & $\begin{array}{l}\not{8} \\
+ \\
\infty \\
\infty\end{array}$ & 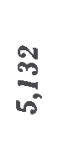 & 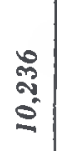 & $\begin{array}{c}\hat{N} \\
\text { si } \\
\text { is }\end{array}$ \\
\hline 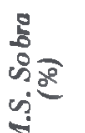 & 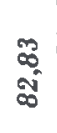 & $\underset{\infty}{\stackrel{+}{\infty}}$ & $\begin{array}{l}\vec{D} \\
\text { : } \\
\infty\end{array}$ & \begin{tabular}{l} 
जे \\
\multirow{\infty}{\infty}{}
\end{tabular} & จู \\
\hline 影 & क & 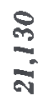 & ลิำ & $\begin{array}{l}\mathfrak{a} \\
\stackrel{a}{=} \\
=\end{array}$ & 可 \\
\hline 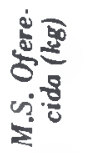 & 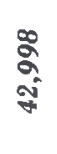 & $\begin{array}{l}\frac{8}{6} \\
\infty^{\circ}\end{array}$ & $\frac{\text { สิ }}{\text { สิ }}$ & 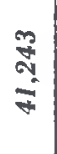 & $\stackrel{\circ}{\circ}$ \\
\hline 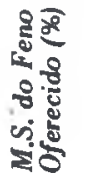 & $\frac{2}{\stackrel{\infty}{\infty}}$ & $\begin{array}{l}\stackrel{2}{2} \\
\stackrel{\infty}{\infty}\end{array}$ & $\stackrel{n}{\frac{2}{\infty}}$ & $\begin{array}{l}2 \\
2 \\
\infty \\
\infty\end{array}$ & 1 \\
\hline 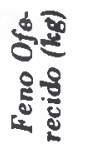 & \begin{tabular}{l}
8 \\
8 \\
\multirow{2}{*}{}
\end{tabular} & $\begin{array}{l}8 \\
8 \\
\$\end{array}$ & § & $\begin{array}{l}8 \\
0 \\
\vdots\end{array}$ & $\frac{8}{a}$ \\
\hline . & - & N & $m$ & 量 & 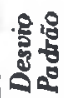 \\
\hline
\end{tabular}

\begin{tabular}{|c|c|c|c|c|c|}
\hline 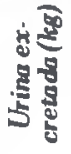 & 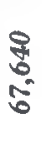 & 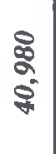 & \begin{tabular}{l}
$R$ \\
\multirow{2}{*}{} \\
0 \\
0
\end{tabular} & 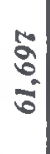 & $\begin{array}{l}\$ 0 \\
8 \\
20\end{array}$ \\
\hline 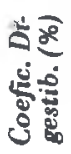 & $\begin{array}{l}\text { is } \\
\text { is }\end{array}$ & $\begin{array}{l}\text { से } \\
\text { जे }\end{array}$ & $\begin{array}{l}\text { Nै } \\
\text { ڤે }\end{array}$ & $\begin{array}{l}\circ \\
0^{\circ} \\
B^{\circ}\end{array}$ & $\frac{7}{0}$ \\
\hline 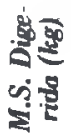 & $\begin{array}{l}\bar{\pi} \\
\text { ลิ }\end{array}$ & $\begin{array}{l}\tilde{\alpha} \\
\vdots \\
=\end{array}$ & $\begin{array}{l}\infty \\
\stackrel{2}{a} \\
\text { สี }\end{array}$ & $\frac{2}{2}$ & $\underset{+}{\$}$ \\
\hline 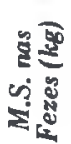 & $\frac{\infty}{\omega^{-1}}$ & $\frac{8}{\infty}$ & $\begin{array}{l}\$ \\
8 \\
\text { is }\end{array}$ & 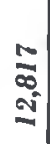 & సે \\
\hline कू & 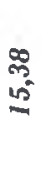 & $\frac{m}{\bar{a}}$ & $\begin{array}{l}\vec{m}^{*} \\
\overrightarrow{2}^{0}\end{array}$ & $\begin{array}{l}\text { ज్ } \\
\stackrel{5}{=}\end{array}$ & $\underset{\sim}{N}$ \\
\hline 造 & $\begin{array}{l}R \\
\qquad \\
\&^{\circ}\end{array}$ & $\begin{array}{l}\underset{N}{R} \\
\stackrel{\infty}{\infty}\end{array}$ & $\begin{array}{l}\stackrel{8}{ } \\
\infty \\
\approx\end{array}$ & 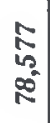 & $\frac{5}{\infty}$ \\
\hline 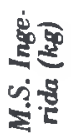 & $\begin{array}{l}\bar{\alpha} \\
\text { ద్ల }\end{array}$ & $\frac{\mathcal{F}}{\stackrel{\text { จ }}{*}}$ & 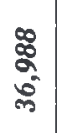 & $\frac{\hat{s}}{8}$ & \begin{tabular}{l}
$\circ$ \\
: \\
\multirow{2}{*}{}
\end{tabular} \\
\hline 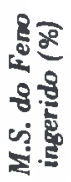 & $\begin{array}{l}\stackrel{2}{2} \\
\stackrel{\infty}{\infty}\end{array}$ & $\begin{array}{l}\stackrel{2}{2} \\
\stackrel{\infty}{\infty}\end{array}$ & $\begin{array}{l}n \\
2 \\
\infty \\
\infty\end{array}$ & $\begin{array}{l}\frac{2}{2} \\
\stackrel{\infty}{\infty}\end{array}$ & 1 \\
\hline 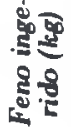 & $\begin{array}{l}\bar{\delta} \\
\text { ळे }\end{array}$ & 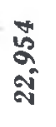 & 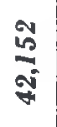 & 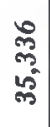 & $\underset{\infty}{R}$ \\
\hline 帠安 & - & N & $m$ & : & 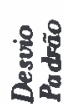 \\
\hline
\end{tabular}

Rev. Fac. Med. vet. Zootec. Univ. S. Paulo, 14(1):101-111, 1977. 
TABELA 3 - Resultados analíticos - nitrogênio

\begin{tabular}{|c|c|c|c|c|}
\hline $\begin{array}{c}\text { Animal } \\
N o\end{array}$ & $\begin{array}{c}\text { N. no Feno } \\
(\%)\end{array}$ & $\begin{array}{c}\text { N. na Sobra } \\
(\%)\end{array}$ & $\begin{array}{c}\text { N. nas Fezes } \\
(\%)\end{array}$ & $\begin{array}{c}\text { N. na Urina } \\
(\%)\end{array}$ \\
\hline 1 & 1,75 & 1,64 & 1,81 & 0,22 \\
\hline 2 & 1,75 & 1,60 & 1,89 & 0,31 \\
\hline 3 & 1,75 & 1,46 & 1,70 & 0,19 \\
\hline Média & 1,75 & 1,57 & 1,80 & 0,24 \\
\hline $\begin{array}{c}\text { Desvio } \\
\text { Padrão }\end{array}$ & - & 0,08 & 0,17 & 0,05 \\
\hline
\end{tabular}

TABELA 4 - Balanço do nitrogênio

\begin{tabular}{|c|c|c|c|c|c|}
\hline $\begin{array}{c}\text { Animal } \\
\text { No }\end{array}$ & $\begin{array}{c}\text { N. Ingerido } \\
\text { c/ feno }(g)\end{array}$ & $\begin{array}{c}\text { N. Excretado } \\
\text { c/ as fezes (g) }\end{array}$ & $\begin{array}{c}\text { N. Excretado } \\
\text { na urina }(g)\end{array}$ & $\begin{array}{c}\text { N. Excretado } \\
\text { Total }(g)\end{array}$ & $\begin{array}{c}\text { Balanço do } \\
\text { N. (g) }\end{array}$ \\
\hline 1 & 621 & 275 & 149 & 424 & 197 \\
\hline 2 & 351 & 155 & 127 & 282 & 69 \\
\hline 3 & 642 & 256 & 145 & 401 & 241 \\
\hline Média & 538 & 229 & 140 & 369 & 169 \\
\hline $\begin{array}{c}\text { Desvio } \\
\text { Padrão }\end{array}$ & 133 & 53 & 10 & 62 & 73 \\
\hline
\end{tabular}

TABELA 5 - Análise bromatológica da proteína bruta

\begin{tabular}{|c|c|c|c|}
\hline $\begin{array}{c}\text { Animal } \\
\text { No }\end{array}$ & $\begin{array}{c}\text { P.B. no Feno } \\
(\%)\end{array}$ & $\begin{array}{c}\text { P.B. na Sobra } \\
(\%)\end{array}$ & $\begin{array}{c}\text { P.B. nas Fezes } \\
(\%)\end{array}$ \\
\hline 1 & 10,94 & 10,25 & 11,31 \\
\hline 2 & 10,94 & 10,00 & 11,81 \\
\hline 3 & 10,94 & 9,13 & 10,63 \\
\hline Media & 10,94 & 9,79 & 11,25 \\
\hline $\begin{array}{l}\text { Desvio } \\
\text { Padrão }\end{array}$ & -- & 0,48 & 0,48 \\
\hline
\end{tabular}


TABELA 6 - Balanço da proteína bruta

\begin{tabular}{|c|c|c|c|c|}
\hline $\begin{array}{c}\text { Animal } \\
\text { No }\end{array}$ & P.B. Ingerida & P.B. Excretada & P.B. Digerida & $\begin{array}{c}\text { P.B. Coefic. } \\
(\mathrm{g})\end{array}$ \\
\hline 1 & 3976 & 1717 & 2259 & 5 Digestib. (\%) \\
\hline 2 & 2377 & 967 & 1410 & 56,82 \\
\hline 3 & 4139 & 1603 & 2536 & 59,32 \\
\hline Média & 3497 & 1429 & 2068 & 61,27 \\
\hline $\begin{array}{c}\text { Desvio } \\
\text { Padrōo }\end{array}$ & 506 & 330 & 479 & 59,14 \\
\hline
\end{tabular}

TABELA 7 - Análise bromatológica do extrato etéreo

\begin{tabular}{|c|c|c|c|}
\hline $\begin{array}{c}\text { Animal } \\
\text { No }\end{array}$ & $\begin{array}{c}\text { E.E. no Feno } \\
(\%)\end{array}$ & $\begin{array}{c}\text { E.E. na Sobra } \\
(\%)\end{array}$ & $\begin{array}{c}\text { E.E. nas Fezes } \\
(\%)\end{array}$ \\
\hline 1 & 2,57 & 1,83 & 2,66 \\
\hline 2 & 2,57 & 2,03 & 2,40 \\
\hline 3 & 2,57 & 1,53 & 2,76 \\
\hline Média & 2,57 & 1,80 & 2,61 \\
\hline $\begin{array}{c}\text { Desuio } \\
\text { Padrōo }\end{array}$ & - & 0,20 & 0,14 \\
\hline
\end{tabular}

TABELA 8 - Balanço do extrato etéreo

\begin{tabular}{|c|c|c|c|c|}
\hline $\begin{array}{c}\text { Animal } \\
\text { No }\end{array}$ & $\begin{array}{c}\text { E.E. Ingerido } \\
(\mathrm{g})\end{array}$ & $\begin{array}{c}\text { E.E. Excretado } \\
(\mathrm{g})\end{array}$ & $\begin{array}{c}\text { E.E. Digerido } \\
(\mathrm{g})\end{array}$ & $\begin{array}{c}\text { E.E. Coefic. } \\
\text { Digestib. (\%) }\end{array}$ \\
\hline 1 & 975 & 404 & 571 & 58,56 \\
\hline 2 & 617 & 197 & 420 & 68,07 \\
\hline 3 & 1003 & 416 & 587 & 58,52 \\
\hline Média & 865 & 339 & 526 & 61,72 \\
\hline $\begin{array}{c}\text { Desvio } \\
\text { Padrio }\end{array}$ & 176 & 101 & 75 & 4,49 \\
\hline
\end{tabular}


TABELA 9 - Análise bromatológica da fibra bruta

\begin{tabular}{|c|c|c|c|}
\hline $\begin{array}{c}\text { Animal } \\
N !\end{array}$ & $\begin{array}{c}\text { F.B. no Feno } \\
(\%)\end{array}$ & $\begin{array}{c}\text { F.B. na Sobra } \\
(\%)\end{array}$ & $\begin{array}{c}\text { F.B. nas Fezes } \\
(\%)\end{array}$ \\
\hline 1 & 30,81 & 23,17 & 20,63 \\
\hline 2 & 30,81 & 21,86 & 24,86 \\
\hline 3 & 30,81 & 21,56 & 20,19 \\
\hline Média & 30,81 & 22,20 & 21,89 \\
\hline $\begin{array}{c}\text { Desvio } \\
\text { Padrão }\end{array}$ & -- & 0,70 & 2,11 \\
\hline
\end{tabular}

TABELA 10 - Balanço da fibra bruta

\begin{tabular}{|c|c|c|c|c|}
\hline$\underset{N o}{A \text { nimal }}$ & F.B. Ingerida & F.B. Excretada & $\begin{array}{l}\text { F.B. Digerida } \\
(g)\end{array}$ & $\begin{array}{l}\text { F.B. Coefic. } \\
\text { Digestib. (\%) }\end{array}$ \\
\hline 1 & 11.601 & 3.132 & 8.469 & 73,00 \\
\hline 2 & 7.859 & 2.036 & 5.823 & 74,09 \\
\hline 3 & 11.871 & 3.045 & 8.826 & 74,35 \\
\hline Média & 10.444 & 2.738 & 7.706 & 73,81 \\
\hline $\begin{array}{l}\text { Desvio } \\
\text { Padrão }\end{array}$ & 1.831 & 497 & 1.339 & 0,59 \\
\hline
\end{tabular}

TABELA 11 - Análise bromatológica dos extrativos não nitrogenados

\begin{tabular}{|c|c|c|c|}
\hline $\begin{array}{c}\text { Animal } \\
\text { No }\end{array}$ & $\begin{array}{c}\text { E.N.N. no Feno } \\
(\%)\end{array}$ & $\begin{array}{c}\text { E.N.N. na Sobra } \\
(\%)\end{array}$ & $\begin{array}{c}\text { E.N.N. nas Fezes } \\
(\%)\end{array}$ \\
\hline 1 & 36,29 & 32,27 & 33,97 \\
\hline 2 & 36,29 & 26,90 & 46,61 \\
\hline 3 & 36,29 & 26,53 & 36,20 \\
\hline Media & 36,29 & 28,57 & 38,93 \\
\hline $\begin{array}{c}\text { Desuio } \\
\text { Padrio }\end{array}$ & -- & 2,62 & 5,51 \\
\hline
\end{tabular}


TABELA 12 - Balanço dos extrativos não nitrogenados

\begin{tabular}{|c|c|c|c|c|}
\hline $\begin{array}{c}\text { Antmal } \\
\text { No }\end{array}$ & $\begin{array}{c}\text { E.N.N. Ingerido } \\
(\mathrm{g})\end{array}$ & $\begin{array}{c}\text { E.N.N. Excrètado } \\
(\mathrm{g})\end{array}$ & $\begin{array}{c}\text { E.N.N. Digerido } \\
(\mathrm{g})\end{array}$ & $\begin{array}{c}\text { E.N.N. Coefic. } \\
\text { Digestib. (\%) }\end{array}$ \\
\hline$I$ & 13.331 & 5.157 & 8.154 & 61,26 \\
\hline 2 & 9.044 & 3.817 & 5.227 & 57,80 \\
\hline 3 & 13.923 & 5.459 & 8.464 & 60,79 \\
\hline Média & 12.093 & 4.811 & 7.282 & 59,95 \\
\hline $\begin{array}{c}\text { Desvio } \\
\text { Padrão }\end{array}$ & 2.170 & 714 & 1.458 & 1,53 \\
\hline
\end{tabular}

mo TABELA I3 - Valores médios dos nutrientes digestiveis do feno

\begin{tabular}{|c|c|c|c|c|c|c|}
\hline $\begin{array}{c}M . S . \\
(\%)\end{array}$ & $\begin{array}{c}\text { P.D. } \\
(\%)\end{array}$ & $\begin{array}{c}\text { E.E.D. }(x 2,25) \\
(\%)\end{array}$ & $\begin{array}{c}\text { F.D. } \\
(\%)\end{array}$ & $\begin{array}{c}\text { E.N.N.D. } \\
(\%)\end{array}$ & $\begin{array}{c}\text { V.D.T. } \\
(\%)\end{array}$ & $\begin{array}{c}\text { Energia Digest. } \\
\text { Kcal/kg }\end{array}$ \\
\hline 51,56 & 6,47 & 3,57 & 22,74 & 21,76 & 54,54 & 2,400 \\
\hline
\end{tabular}

variedade Napier, encontraram valores superiores para P.B. 13,46\%; E.E. 3,35\%; F.B. $31,73 \%$ e E.N.N. $42,36 \%$.

Referindo-se, novamente, à idade de corte do capim, 63 dias, esta situa-se no intervalo de cortes do experimento de MELOTTI \& PEDREIRA ${ }^{8}$ (1970/71), 58 e 66 dias de idade; contudo observou-se teores incompatíveis com os constatados por aqueles autores; conforme tabela no 14.

Considerando os resultados do presente ensaio, e com base no trabalho de PE. DREIRA $^{12}$ (1973) que mediu o efeito da estacionalidade da produção de forrageiras no Brasil Central ( 80 a $90 \%$ no verão e 10 a $20 \%$ no inverno), fica evidente que a confecção de feno é uma prática aconselhável para o aumento da produtividade da pecuária brasileira.

A variedade Napier utilizada na confecção do feno em estudo, mostrou-se bastante produtiva e de valor nutritivo elevado quando cortada em idade não muito avançada, SILVA ${ }^{14}$ (1965), FONSECA ${ }^{4}$ (1965), VIEIRA \& GOMIDE $^{17}$ (1968), SILVEIRA et alii $^{16}$ (1974), em concordância com as conclusões tiradas do trabalho de SILVA \& GOMIDE $^{15}$ (1967), sobre idades diferentes ao corte, num estudo de digestibilidade com carneiros.

\section{CONCLUSĀO}

Concluiu-se do presente trabalho, que embora a produção de Matéria seca por área do capim-elefante variedade Napier, seja relativamente menor nos cortes efetuados com altura inferior a $1,00 \mathrm{~m}$ (BRITTO et alii $^{3}$ 1975); a qualidade do feno confeccionado nessas condições, justifica esse procedimento, conforme os dados obtidos (a despeito da incidência de chuvas sobre o material, por ocasião da secagem).

\section{AGRADECIMENTOS}

Os autores agradecem ao Engenheiro Agrônomo Nicolino Lombardi Jr., Gerente Técnico da Fazenda Mundo Novo - Brotas - S.P., pelo fornecimento do feno, assim como dos dados de adubação e desenvolvimento fisiológico da planta forrageira. 
TABELA 14 - Comparação de análises bromatológicas do capim-elefante em diferentes idades

\begin{tabular}{|l|c|c|c|}
\hline \multicolumn{1}{|c|}{ Autores } & $\begin{array}{c}\text { MELOTTI } \\
\text { \& } \\
\text { PEDREIRA } \\
(1970 / 71)\end{array}$ & $\begin{array}{c}\text { VELLOSO } \\
\text { et alii } \\
(1977)\end{array}$ & $\begin{array}{c}\text { MELOTTI } \\
\text { \& } \\
\text { PEDREIRA } \\
(1970 / 71)\end{array}$ \\
\hline $\begin{array}{l}\text { Nu. Idade de } \\
\text { trientes }\end{array}$ & 58 dias & 63 dias & 66 dias \\
\hline P.B. & $7,01 \%$ & $10,94 \%$ & $7,73 \%$ \\
\hline E.E. & $3,56 \%$ & $2,57 \%$ & $3,12 \%$ \\
\hline F.B. & $33,77 \%$ & $30,81 \%$ & $36,38 \%$ \\
\hline E.N.N. & $43,08 \%$ & $36,29 \%$ & $38,59 \%$ \\
\hline
\end{tabular}

RFMV-A/13

VELLOSO, L.; NOVAES, W.C.; VILLELA, R.L.; OLIVEIRA, L.P. Nutritive value of an Elephant Napiergrass hay (Pennisetum purpureum, Schum), as determined through a digestion trial with steers in cages. Rev. Fac. Med. vet. Zootec. Univ. S.Paulo, 14(1): 101.111, 1977.

SUMMARY: Three crossbred Holstein steers were used in a digestion trial (in cages), to determine the nutritive value of an Elephant Napiergrass hay. Collection period lasted for seven days (after five days of adaptation to the feed and three days to the cages). Chemical composition of hay was a follows: Dry matter (DM) 87,75\%; Crude protein (CP) 10,94\%; Ether extrat (EE) 2,57\%; Crude fiber (CF) $30,81 \%$; Nitrogen free extract (NFE) $36,29 \%$. Data for coeficients of digestibility were as follows: DM 58,76\%; CP $59,14 \%$; EE 61,72\%; CF 73,81\%; NFE 59,95\%, being the Total Digestible Nutrients equal to $54,54 \%$

UNITERMS: Food digestibility * Hay *; Forrage *.

\section{REFERÊNCIAS BIBLIOGRÄFICAS}

1 - ANDRADE, I.F. \& GOMIDE, J.A. Curva de crescimento e valor nutritivo do capim-lefante (Pennisetum purpureum, Schum). Rev. Soc. bras. Zootecs, Viçosa, 1(1): 41-58, 1972.

2 - A.O.A.C. Official methods of analysis. 8.ed. Washington, 1955. $1008 \mathrm{p}$.

3 - BRITTO, D.P.P.S.; ARONOVICH, S.; RIBEIRO, H. Comparação de duas variedades de capimelefante (Pennisetum purpureum, Schum) e de seis diferentes espaços de tempo entre os cortes das plantas. CONGRESSO INTERNACIONAL DE PASTAGENS, 9., São Paulo, 1965. Anais. p.1683-85.

4 - FONSECA, J.B.; CAMPOS, J.; CONRAD, J.H. Estudo de digestibilidade de forrageiras tropicais pelo processo convencional. CONGRESSO INTERNACIONAL DE PASTAGENS, 9., Sāo Paulo, 1965 . Anais. p.807-8.

5 - KOK, E.A.; MACHADO, L.B.; ROCHA, G.L. Valor nutritivo de plantas forrageiras. Bol. Ind. anim., São Paulo, $8(3): 18-44,1946$.

6 - McDONALD, P.; EDWARDS, R.A.; GREENHALGH, J.F.D. Animal nutrition. 2.ed. Edinburgh, Oliver \& Boyd, 1973. 479p.

7 - MELOTTI L. \& LUCCI,C.S. Determinação do valor nutritivo dos capins-elefante Napier (Penniset um purpureum, Schum) e fino (Brachiaria mutica), atravếs de ensaio de digestibilidade ( $\mathrm{a}$ parente) com carneiros. Bol. Ind. anim., São Paulo, 26(único): 275-84, 1969. 
8 - MELOTTI, L. \& PEDREIRA,J.V.S. Determinação do valor nutritivo dos capins-elefante Napier (Pennisetum purpureum, Schum) e Guatemala (Tripsacum laxum, Nash) em dois estádios de maturação; através de ensaio de digestibilidade (aparente) com carneiros. Bol. Ind. anim., São Paulo, 27/28(único): 207-22, 1970/71.

9 - MUNIZ, N.R.; GARCIA, R.; CHRISTMAS, E.P.; GOMIDE, J.A. Estudo de manejo de uma capineira de capim-elefante "Mineiro" (Pennisetum purpureum, Schum). Rev, Soc. bras. Zootec., Viçosa, 1(1): 1-23, 1972.

10 - PACOLA, L.J.; LIMA, F.P.; CAMPOS, B.E.S. Apetibilidade e produçāo de oito variedades do capim-elefante (Pennisetum purpureum, Schum). Bol. Ind. anim., São Paulo, 31(1): 91-6, 1974.

11 - PACOLA, L.J.; LIMA, F.P.; SANTOS, O.L.; CAMPOS, B.E.S. Apetibilidade do capim-elefante (Pennisetum purpureum, Schum). Bol. Ind. anim., São Paulo, 29(1): 169-73, 1972.

12 - PEDREIRA, J.V.S. Crescimento estacional dos capins colonião (Panicum maximum, Jacq), gordura (Melinis minu. tiflora, Pal de Beauv), jaraguá (Hyparrhenia rufa, (Ness) Stapf) e pangola de Taiwan A-24 (Digitaria pentzii, Stent). Bol. Ind. anim., São Paulo, 30(1): 59-145, 1973.
13 - PEDREIRA, J.V.S.; NUTI, P.; CAMPOS, B.E.S. Competição de cinco variedades de capim-elefante (Pennisetum purpureum, Schum). Bol. Ind. anim., Sāo Paulo, 32(2): 325-29, 1975 .

14 - SILVA, D.J.; CONRAD, J.H.; CAMPOS, J. Da digestibilidade "in vitro" de algumas forrageiras tropicais. CONGRESSO INTERNACIONAL DE PASTAGENS, 9., 1965. Anais. p.807-8.

15 - SILVA, J.F.C. \& GOMIDE, J.A. Efeito do estágio de maturação sobre o consumo e digestibilidade aparente de Matéria seca de três gramíneas tropicais. Rev. Ceres, Viçosa, 13(76): 255-75, 1967.

16 - SILVEIRA, A.C.; TOSI, H.; FARIA, V.P. Efeito da maturidade sobre a composição química bromatológica do capim Napier (Pennisetum purpu. reum, Schum). Rev. Soc. bras. Zoo. tec., Viçosa, 3(2): 158-71, 1974.

17 - VIEIRA, L.M. \& GOMIDE, J.A. Composição química e produção forrageira de três variedades de capim-elefante. Rev. Ceres, Viçosa, 15(86): 245-60, 1968 .

Recebido para publicaçăo em 1-3-77 A provado para publicaçāo em 3-8-77 